Letters to the Editor

\section{Angiofollicular lymph node hyperplasia}

The exact nature of angiofollicular lymph node hyperplasia (AFLNH) is unknown.' Hyperplasia as a response to abnormal host reaction, ${ }^{1}$ harmartoma, ${ }^{2}$ and neoplasia ${ }^{3}$ have all been suggested. It has occurred in men at risk of acquired immune deficiency syndrome (AIDS), ${ }^{4}$ usually in association with Kaposi's sarcoma in, or draining to, affected nodes. We report the development of AFLNH in a patient receiving therapeutic immunosuppression, supporting the suggestion that abnormal immunoregulation predisposes to AFLNH. ${ }^{s}$

Three years after a cadaveric renal transplant a 29 year old woman complained of prolonged malaise, nausea, and weakness. Two early rejection episodes had been treated with three doses of methyl prednisolone $0.5 \mathrm{~g}$ and she was then maintained on prednisolone $10 \mathrm{mg}$ with azathioprine $100 \mathrm{mg}$ daily. Physical examination and investigations yielded normal results, apart from circulating immune complexes containing $\mathrm{Clq}$, and three months after onset of symptoms a soft enlarged right axillary lymph node was noted. A biopsy specimen of the node $(1.4 \times 0.7 \times 0.5 \mathrm{~cm})$ showed features of the hyaline vascular type of AFLNH (figs 1 and 2).

A chest $x$-ray picture and computed tomography scan excluded the possibility of larger nodes with AFLNH or occult malignancy draining to the axilla. Viral titres did not indicate any recent infection with cytomegalovirus; HIV antibody test was negative as was a test for hepatitis B surface antigen. Three years after presentation she remained well with good renal function and gave birth to a healthy baby.

The lymph node was small compared with other localised cases of AFLNH. The patient was symptomatic and the symptoms disappeared after removal of the node. This course is more commonly associated with the localised plasma cell type of AFLNH, and occasionally with the localised hyaline vascular type.

In the context of patients who do not have HIV infection, AFLNH is not uncommon. It has been described in many different and variable clinical settings, ranging from genetically determined immunodeficient states and in various autoimmune diseases to an idiopathic condition. To our knowledge

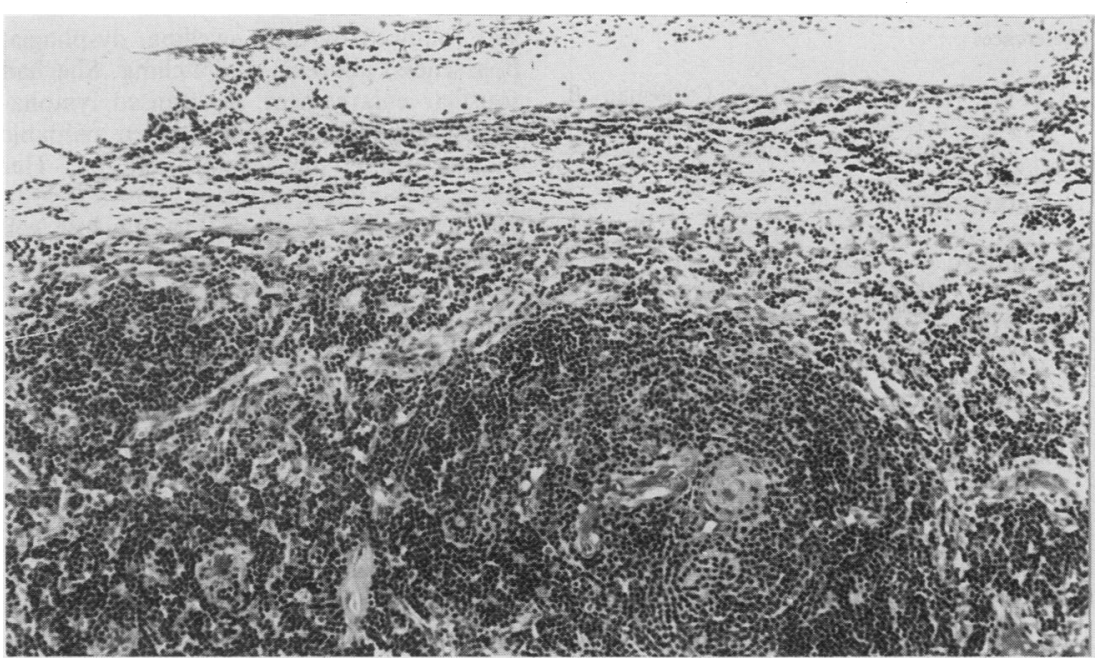

Fig 1 AFNLH with extension of small lymphoid cells into capsule and just into perinodal fat.

therapeutic immunosuppression has not previously been implicated as a cause of solitary AFLNH.

In patients with immunodeficiency AFLNH is usually of the plasma cell type, ${ }^{4}$ and in our and Harris's experience is often associated with Kaposi's sarcoma.

Perhaps therapeutic immunosupression can predispose to the development of AFLNH, although the cause is still not known. The initial illness may have been viral and this case may represent an unusual response to viral antigen, but there was no serological evidence of recent infection. This case also supports the view that a basic abnormality of immunoregulation results in rather than from AFLNH. This has important implications in the aetiology and treatment of this poorly understood condition.

ND FRANCIS, K HOLLOWOOD

R GABRIEL,

St Mary's Hospital Praed Street,

London W2 INY

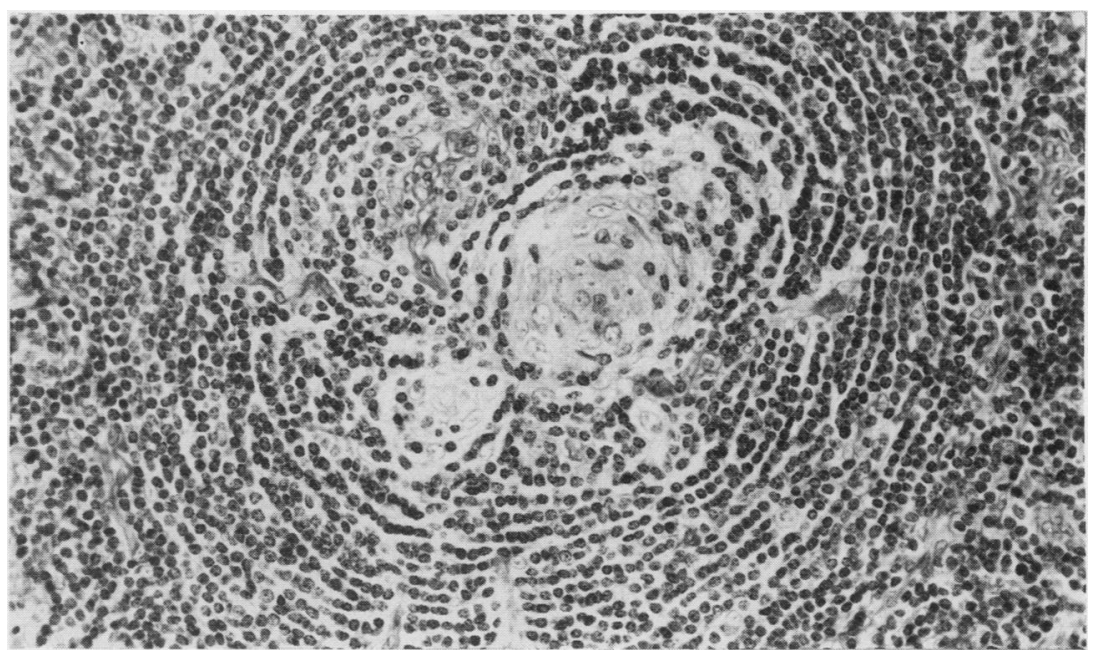

Fig 2 Typical appearance of hyaline vascular type of AFLNH, with hyalinised central vessel, prominent endothelial cells, and concentric arrangement of surrounding small lymphocytes. (PAS stain.) 


\section{References}

1 Keller AR, Hochholzer L, Castleman B. Hyaline vascular and plasma cell types of giant lymph node hyperplasia of the mediastinum and other locations. Cancer 1972;29:670-83.

2 Abel MR. Lymph nodal hamartoma versus thymic choriostoma of pulmonary hilum. Arch Pathol Lab Med 1957;64:584-8.

3 Zettergren L. Probable neoplastic proliferation of lymphoid tissue (follicular lymphoreticuloma). Acta Pathologica et Microbiologica Scandinavica 1961;51:11326.

4 Harris ML. Hypervascular follicular hyperplasia and Kaposi's sarcoma in patients at risk for AIDS. N Engl J Med 1984;310:462-3.

5 Jones EL, Croker J, Gregory JL, Guibarra M, Curran RC. Angiofollicular lymph node hyperplasia (Casatleman's disease): an immunohistochemical study of the hyalinevascular form of the lesion. $J$ Pathol 1984;144:131-47.

Terminal deoxynucleotidyl transferase (Tdt) and positive immunoblastic lymphoma

Terminal deoxynucleotidyl transferase (Tdt) is a specific marker for immature lymphoid cells; it is localised to the nucleus and catalyses the polymerisation of deoxynucleotide monophosphates without the use of a template. Immature lymphoid malignancies are usually Tdt positive, and mature lymphoid neoplasms such as multiple myeloma, chronic lymphatic leukaemia, Sezary's syndrome, hairy cell leukaemia, Burkitt's lymphoma and cell acute lymphoblastic leukaemia, are Tdt negative.

A 62 year old caucasian women presented with a four month history of hip and abdominal pain and a $6 \mathrm{~kg}$ weight loss, which was followed by neck swelling, dysphagia, hoarseness, anorexia and itching. She had tonsillar enlargement, generalised lymphadenopathy, and a tender spleen palpable $5 \mathrm{~cm}$ from the costal margin. Her haemoglobin concentration was $9.6 \mathrm{~g} / \mathrm{dl}$, platelet count $246 \times 10^{9} / 1$, and white cell count $5.2 \times 10^{9} / 1$ with a normal differential. Bone marrow aspirate was hypercellular containing $97 \%$ blasts, large cells of 20-25 $\mu \mathrm{m}$ in diameter with delicate chromatin and plentiful basophilic granular cytoplasm; most had a single large central nucleolus, some possessed two to four small nucleoli. A marrow trephine biopsy specimen showed almost complete replacement by blast cells, and a tonsil biopsy specimen showed a diffuse infiltrate of very similar cells. Serum immunoelectrophoresis indicated immunoparesis and her urine contained $\kappa$ light chain Bence Jones protein. A chest $x$ ray picture showed there was an anterior mediastinal mass, and abdominal ultrasound scan showed severe enlargement of para-aortic lymph nodes. Intensive chemotherapy was started, but following a brief remission, the patient relapsed and died 13 months later.

The results of immunophenotyping of peripheral blood, marrow aspirate, and marrow trephine biopsy are shown in the table. Over $90 \%$ of marrow aspirate blasts were Tdt positive, and in a separate analysis of the frozen trephine biopsy specimen, over $80 \%$ of the blasts were Tdt positive. Ninety five per cent of marrow aspirate blasts stained for monoclonal surface immunoglobulin $\operatorname{IgM} \kappa$, and $80 \%$ of blasts in a frozen trephine biopsy specimen also stained for monoclonal surface $\kappa$ light chain. The trephine biopsy blast population was also positive for J5 (anti-CALLA) and over $25 \%$ of cells were positive for the proliferation marker Ki67. Both aspirate and trephine biopsy specimens were negative for $T$ cell markers.

A recent review of published data showed that 24 cases of B cell lymphoma were all negative for Tdt, but two of 48 cases of B cell ALL described were Tdt positive. ${ }^{12}$ Two possible explanations were proposed.
Firstly, that an intermediate stage exists between pre-B ALL and B-ALL in which the $\vec{\sigma}$ maturation of these two B cell leukaemias had been arrested, and secondly, that expres- $\vec{F}$. sion of CALLA and Tdt on SmIg positive ? cells is due to an uncoupling of normal maturation in neoplastic cells.

The morphology of the marrow aspirate in $\frac{\overline{\bar{S}}}{\bar{D}}$ this case indicated that the blasts were fur- $\mathbb{D}$ ther along the accepted pathway of B cell maturation than the blasts in B-ALL, and ${ }^{\infty}$ yet these immunoblasts still expressed $\vec{O}$ CALLA and Tdt. We propose that an uncoupling of normal maturation is the $\vec{\omega}$ likeliest explanation for the immunological profile observed.

\section{References}

DM WHITE, AG SMITH, $\vec{\omega}$ JL SMITH Department of Haematology, 心 Royal South Hants Hospital, Southampton SO9 4PE

1 Drexler HE, Menon M, Minowada J. Incidence $\overrightarrow{0}$ of Tdt positivity in cases of leukaemia and $\infty$ lymphoma. Acta Haematol 1986;75:12-17.

2 Shaw MT, Dwyer JM, Allaudlen HS, Weitzmano HA. Terminal deoxynucleotidyl transferase activity in B-cell acute lymphocytic leukaemia. Blood 1978;51:182-7.

Immunological phenotypes of blood and marrow cell populations expressed as percentage of positive cells

\begin{tabular}{|c|c|c|c|c|c|c|c|c|c|c|c|c|c|}
\hline & \multicolumn{2}{|c|}{$P A N T$} & \multirow{2}{*}{$\frac{C A L L A}{C D 10}$} & \multirow{2}{*}{$\frac{P A N B}{C D 37}$} & \multicolumn{3}{|c|}{$H L A C L A S S$} & \multicolumn{6}{|c|}{ Surface immunoglobulin (Ig) } \\
\hline & $C D 3$ & CD7 & & & $\overline{I I}$ & Ki67 & $T d t$ & $G$ & $A$ & $M$ & $D$ & $\kappa$ & $\lambda$ \\
\hline $\begin{array}{l}\text { Peripheral blood } \\
\text { Marrow aspirate } \\
\text { Marrow* trephine biopsy specimen }\end{array}$ & $\begin{array}{l}83 \\
2 \\
<10\end{array}$ & $\begin{array}{r}55 \\
4\end{array}$ & $\begin{array}{l}\text { ND } \\
\text { ND } \\
>90\end{array}$ & $\begin{array}{l}\overline{N D} \\
60\end{array}$ & $\begin{array}{l}16 \\
95 \\
\text { ND }\end{array}$ & $\begin{array}{l}\text { ND } \\
\text { ND } \\
>25\end{array}$ & $\begin{array}{l}30 \\
>90 \\
>80\end{array}$ & $\begin{array}{l}\text { ND } \\
\mathbf{0} \\
\text { ND }\end{array}$ & $\begin{array}{l}\text { ND } \\
0 \\
\text { ND }\end{array}$ & $\begin{array}{l}\text { ND } \\
95 \\
\text { ND }\end{array}$ & $\begin{array}{l}\text { ND } \\
0 \\
\text { ND }\end{array}$ & $\begin{array}{l}20 \\
95 \\
80\end{array}$ & $\begin{array}{l}1 \\
0 \\
0\end{array}$ \\
\hline
\end{tabular}

*The marrow aspirate contained $4 \%$ plasma cells, and the trephine biopsy specimen $5 \%$ plasma cells staining for cytoplasmic IgG $\lambda$. 